\title{
MIGRAÇÃO NEGRA INTERNA E IDENTIDADE CULTURAL NO QUILOMBO DO AMÉRICA: UMA CONTRIBUIÇÃO
}

\author{
Ketno Lucas Santiago ${ }^{1}$ \\ Francisco Pereira Smith Júnior ${ }^{2}$ \\ Ana Paula Vieira e Souza ${ }^{3}$
}

\begin{abstract}
RESUMO
Esta pesquisa é fruto de uma revisão bibliográfica sobre a categoria migração, cujo enfoque do objeto de estudo é a migração negra, bem como os estudos acerca da identidade cultural na constituição da comunidade Quilombola do América, localizado no município de Bragança, Estado do Pará. O objetivo principal, é o de localizar estudos que tratam de questões como migração, migração negra e migração forçada e interna. Articular os movimentos migratórios com os estudos desenvolvidos sobre questões culturais produzida pela população quilombola, bem como apontar indicativos para a constituição de uma visão identitária na formação destes povos tradicionais. Metodologicamente o caminho percorrido é de cunho historiográfico, por meio de uma revisão bibliográfica, identificando teorias que contribuíram para estabelecer um diálogo entre as categorias sugeridas. Inicialmente os resultados apontam que a chegada dos africanos no Brasil e na Região da Amazônia Bragantina, se deu por meio de um processo de migração negra forçada e migração interna. O fator econômico é a hipótese predominante, que motivou o deslocamento desta população. A autoidentificação é uma visão de pertencimento, apresenta alguns indícios do caráter identitário e cultural dos remanescentes quilombolas. Concluímos que foi possível identificar alguns autores que abordam sobre a questão migração e suas variações, autores que dialogam com a temática identidade e cultura. Foi possível identificar, de forma preliminar, que a identidade cultural da população quilombola tem traços decorrentes da sua pertença e resistência contra as formas de opressão e de violação de seus direitos como moradores do Quilombo do América ao longo dos anos.
\end{abstract}

Palavras-chave: Migração Negra. Identidades. Culturas.

\begin{abstract}
This research is the result of a bibliographical review on the migration category, whose focus is the black migration, as well as the studies about the cultural identity in the Quilombola community of America, located in the city of Bragança, State of Pará The main objective is to locate studies that deal with issues such as migration, black migration and forced and internal migration. Articulate the migratory movements with the studies developed on cultural issues produced by the quilombola population, as well as indicate indicatives for the constitution of an identity vision in the formation of these traditional peoples. Methodologically, the path covered is a historiographical one, through a bibliographical review, identifying theories that contributed to establish a dialogue between the suggested categories. Initially the results indicate that the arrival of Africans in Brazil and in the Bragantina Amazon Region occurred through a process of forced black migration and internal migration. The economic factor is the predominant hypothesis, which motivated the displacement of this population. Self-identification is a vision of belonging, presents some evidence of the identity and cultural character of the remaining quilombolas. We conclude that it was possible to identify some authors that approach on the issue of migration and its variations, authors that dialogue with the

\footnotetext{
${ }^{1}$ Acadêmico do Mestrado do Programa de Pós-Graduação em Linguagens e Saberes da Amazônia - PPLSA/ Campus Bragança (UFPA). Especialista na Docência do Ensino Superior, Historiador. Membro do GELCONPE. E-mail: ketnolucas@gmail.com

2 Professor Doutor Adjunto III (UFPA). Vice-coordenador do Programa de Pós-graduação em Letras, Linguagens e Saberes na Amazônia (PPLSA). Coordenador do Grupo de Estudos de Literatura Comparada do Nordeste Paraense - GELCONPE. E-mail: fsmith@ufpa.br

${ }^{3}$ Professora Doutora em Educação (UFPA). Professora do Programa de Mestrado em Linguagem e Saberes da Amazônia, (PPLSA-UFPA). Coordenadora do GEPTE/Infância. E-mail: paulladesa@ufpa.br
} 
thematic identity and culture. It was possible to identify, in a preliminary way, that the cultural identity of the quilombola population has traits due to their belonging and resistance against the forms of oppression and violation of their rights as inhabitants of Quilombo of America over the years.

Keywords: Black Migration. Identities. Cultures.

\section{CONSIDERAÇÕES INICIAIS}

A migração negra é um fenômeno constituído ao longo da história da humanidade, um processo de deslocamento da população negra de sua terra natal, para outro território, de forma compulsória, forçados a sair de sua terra de origem, e levados a se estabelecerem em outros territórios no mundo, sobretudo na Europa, na América do Norte e na América do Sul, como foi o caso histórico do escravismo no Brasil. Se diferencia do conceito de Migração, apresentada por Sayad (1998) que é realizado de forma espontânea e possuem várias motivações.

As motivações para o deslocamento do povo negro internamente no país, aqui identificada de Migração Negra Interna, pode ser encontrada no conceito de Costa (2007), ao abordar o processo migratório da população recém liberta da escravidão, que realizava uma migração em busca de trabalho e de melhores condições de vida, da cidade para o campo, e do campo para a cidade, afinal, "os ex-escravos, marcados pelo legado da escravidão, não conseguiram, salvo raras exceções, competir com o estrangeiro no mercado de trabalho" (COSTA, 2007, p 341). A população negra foi historicamente forçada a deixar o seu local de origem e se deslocar para outras localidades, com o objetivo de garantir a sua subsistência.

Ao chegar no Brasil e na Região da Amazônia Bragantina essa população se estabelece, constituem famílias, utilizam os recursos naturais para garantir a sua subsistência, até se estabelecer e constituir uma identidade cultural, um "pertencimento" (HALL, 2006, p. 08), constituem e estabelecem as suas “culturas étnico-raciais” (COELHO, 2014).

A cultura, a identidade e a migração negra desses povos remanescentes de quilombos, foi objeto de pesquisa nas atividades acadêmicas, realizadas por meio de discussões realizadas na Disciplina Identidade, diversidade cultural e populações da Amazônia: diálogos sobre modernização e territorialidades ${ }^{4}$. Essa produção textual foi realizada como critério de avaliativo e se propôs a relacionar os estudos em sala de aula, com a temática "Migração negra interna: A constituição a população afro-brasileira no Quilombo do América” é objeto

\footnotetext{
4 Disciplina Identidade, diversidade cultural e populações da Amazônia: diálogos sobre modernização e territorialidades, ministrada pelo Prof. Dr. César Augusto Martins de Souza, do Programa de Mestrado em Linguagem e Saberes da Amazônia, (PPLSA-UFPA).
} 
de pesquisa do Programa de Mestrado em Linguagens e Saberes da Amazônia (PPLSA/UFPA Campus Bragança), que se articulando principalmente, com os estudos sobre o conceito de identidade e culturas na migração negra interna e a comunidade do Quilombo do América.

Neste estudo localizamos pesquisas por meio de uma revisão bibliográfica, com critérios acerca das categorias de migração, com enfoque na migração negra, bem como autores e pesquisas que tratam sobre a identidade e cultura, com o objetivo de identificar estudos que tratam sobre as temáticas de migração. Relacionar esses movimentos migratórios com os estudos sobre questões culturais, desenvolvidas em comunidades tradicionais, principalmente nos quilombos, apontar indicativos para a visualizar a identidade destes remanescentes quilombolas.

\section{DiÁlogos BIbLiOgRÁfiCOS: MIGRAÇÃO, E MIGRAÇÃo NEGRA E FORÇADA.}

Localizamos estudos que se referem a chegada dos africanos na Amazônia Paraense, introduzidos por meio do tráfico de escravos, datado do final do século XVII, pelos ingleses, inicialmente, a migração esteve relacionada no discurso ideológico de investimento na agricultura, posteriormente, pelos espanhóis com a mesma finalidade de investir no cultivo agrícola. O autor Bezerra Netto (2012, p. 27) diz que "em 1692, por exemplo, a Câmara de Vereadores de Belém solicitava a El-Rei medidas relativas ao fornecimento de escravos africanos", indica, portanto, a questão de um processo migratório realizado de forma forçada, instrumento usado para elevar a economia pelo viés político e social, carregado de violência, de marginalização e exclusão social do negro de origem africana.

O processo de marginalização e exclusão social da população escravizada vindo do Continente da África e de seus descendentes para o Brasil é histórico, perpassou o período da escravidão segundo Costa (2007, p. 341). “O negro será um marginal e desenvolverá formas de comportamento típicas do marginalismo". Durante a escravidão o comércio escravagista funcionou pelo sistema de compra e venda de pessoas negras, tratadas como escravos, tendo sido a sua força de trabalho utilizada na agricultura, mineração, trabalhos domésticos e outras formas de servidão.

A migração negra forçada, foi um processo de tráfico de pessoas, durou mais de três séculos até a proibição, impulsionada pela mudança nas formas de trabalho na Grã-Bretanha no começo do Século XIX (GLEDHILL, 2014, p.24). No cenário Brasileiro, o fim do tráfíco negreiro não acorreu em 1831. Com a publicação da Lei Feijó, que declarava livres todos os 
escravos vindos de fora do Império, e impõe penas aos importadores dos mesmos escravos (BRASIL, 2012, p. 69) $)^{5}$ O fim do tráfico ocorreu tardiamente, em 1850, com a publicação da Lei Euzébio de Queiroz, proibindo a entrada de pessoas da África (BRASIL, 2012, p. 159) ${ }^{6}$, embora a liberdade do negro somente tenha acontecido com a publicação da Lei Áurea, $\mathrm{N}^{\circ}$ 3.353 de 1888, que declarou extinta a escravidão no país (BRASIL, 2012, p 469) ${ }^{7}$.

No escravismo, homens, mulheres e crianças negras foram obrigadas a migrarem para outros países do mundo via atlântico, muitos morreram nessa travessia antes de chegarem ao destino. A população negra foi utilizada como mão de obra escrava, submetida ao trabalho obrigatório pela trajetória da migração compulsória, diferentemente da concepção de migração.

A migração, na concepção de Sayad (1998, p.15), acontece dentro de um espaço físico e social, tendo o sentido de ocupação do espaço territorial e de distribuição populacional, bem como implicando problemas que envolvem um espaço qualificado em vários sentidos, "socialmente, economicamente, politicamente, culturalmente" (SAYAD, 1998, p.15).

Assim, a migração de um espaço geográfico para outro acontece por uma tomada de decisão do migrante, representa uma ação originada por pessoas com diversas motivações, e carrega "sentimentos humanos, como o desejo em encontrar uma vida nova, alavancada pela esperança de vida próspera, de habitar em locais favoráveis a vida tranquila, por exemplo, distante principalmente de guerras e calamidades naturais" (SMITH JÚNIOR, 2012 p.19).

Esse processo tem subjacente geralmente fatores econômicos, políticos e sociais que motivam o processo de deslocamento de pessoas. Mas o interesse em migrar, não está apenas relacionado com fenômenos como: a guerra, a fome e a miséria, relaciona-se também com razões de caráter social, cultural, antropológico, científico, religioso, histórico, entre outros" (SMITH JÚNIOR, 2012, p.19), que se distinguem da concepção de migração forçada da população negra originária do Continente Africano pelo sistema do escravismo.

A distinção entre migração e migração negra forçada diz respeito, pois, às motivações, uma vez que o negro não escolheu migrar por condicionantes de sua expulsão e atração conforme explícito por Klein (2000), tampouco o negro estava fugindo da fome, em busca de trabalho ou de melhor situação para morar. A migração negra forçada esteve relacionada à escravidão e ao tráfico de seres humanos, impulsionada pelos fatores já assinalados.

\footnotetext{
${ }^{5}$ BRASIL. A Abolição no Parlamento: 65 anos de luta, (1823-1888) / Apresentação do presidente José Sarney. - 2a ed. - Brasília: Senado Federal, Secretaria Especial de Editoração e Publicações, 2012. v. 1 e v. 2. Acessado no 18/05https://goo.gl/TTf9PV

6 _. Id. 2012. p. 159.

7 . Id. 2012. p. 469.
} 
O movimento migratório nem sempre é considerado como uma mudança voluntária, todavia existem outras formas de migração, como um "movimento contínuo de grupos sociais diferenciados, entre estruturas socioespaciais específicas, cujas intra e inter-relações determinam a dinâmica do processo" (TAVARES, 2001, p. 02).

A migração no dizer Klein (2000, p. 14) é uma ação justificada por fatores de "expulsão" e de "atração", e de como estes interagem determinando a dinâmica de migrar. Para este autor, o principal motivo da "expulsão" de pessoas são as condições econômicas, destacando três condicionantes: "o primeiro é o acesso à terra e, portanto, ao alimento; o segundo, a variação da produtividade da terra; e o terceiro, o número de membros da família que precisam ser mantidos" (KLEIN, 2000, p.14).

Esses fatores influenciadores do ato de migrar apontados como "expulsão" e "atração" de pessoas, na argumentação de Klein (2000, p. 15) são relacionados aos acontecimentos históricos do século XVIII, período cujas taxas de mortalidade se mantiveram estáveis, tempo de crescimento dos índices de natalidade. Esse crescimento populacional pressionou o setor agrícola para garantir mais alimentos e terra para as populações que se deslocassem em condições de permanência para se fixarem em outros espaços geográficos.

O fator de atração dos imigrantes para Klein (2000) é determinado por melhores condições para os povos em se fixar e se adaptar, marcados pelas condicionantes conjunturais, referindo Klein (2000) aos exemplos da Europa e da América. Se, no continente europeu, "a terra era cara e a mão-de-obra, barata"; no continente americano "a terra era abundante e estava disponível. Entretanto, a mão-de-obra era escassa; portanto, cara” (KLEIN, 2000, p.15).

No caso da América do Sul a colonização necessitava de mão de obra para garantir a sua ocupação e de seus colonizadores, tendo intensificado o tráfico de negros para trabalharem como escravos. A migração negra forçada chegou ao Brasil e se expandiu para diversas regiões, dentre elas, a Região Amazônica, (Estados e Províncias).

A constituição do negro no Brasil ocorreu pela migração negra forçada. As modificações no sistema escravista são geradas pelo modo de produção do trabalho, fruto do capitalismo dependente (COSTA, 2007), pois o Brasil vivenciava a modernização pelo desenvolvimento industrial e pela urbanização de grandes cidades, como o Rio de Janeiro e São Paulo na Região Sudeste, na Região Norte foram as cidades de Belém e Manaus no contexto da Região Amazônica.

Consideramos, portanto, que no cenário da abolição da escravidão, o negro não foi incluído no processo, pois a Lei Áurea foi restrita ao libertá-los sem reforma social, uma vez 
que a população negra não teve condições econômicas e financeiras para a sua própria sobrevivência. O deslocamento da população negra de uma região para outra localidade do Brasil a fim de procurar trabalho, pois as mudanças estruturais ocorridas no país pelo processo de "urbanização e industrialização" (COSTA, 2007, p. 253) contribuíram economicamente com a migração interna do negro e na formação da população afro-brasileira entre final do século XIX e começo do século XX.

As modificações no sistema escravista são geradas pelo modo de produção do trabalho, fruto do capitalismo dependente (COSTA, 2007), pois o Brasil vivenciava a modernização, o desenvolvimento industrial e a urbanização das grandes cidades, como foram os casos do Rio de Janeiro, São Paulo, e também as cidades de Belém e Manaus no contexto da Região Amazônica.

A abolição foi restrita ao libertá-los e sem reforma social, os negros ficaram sem condições econômicas e financeiras de sobrevivência, tendo criado espaços de moradia, o seu próprio meio de subsistência, se constituindo em favelas, cortiços, espaços públicos, entre outros, ainda se deslocaram para diferentes lugares que possibilitasse trabalho, alimentação e local de habitação como Mocambos e Quilombos.

Essas transformações econômicas, decorrentes do processo de urbanização e industrialização no país, contribuíram para o deslocamento da população negra para outras regiões do Brasil, cuja migração interna entre províncias, tinha como foco a busca por melhores condições de vida, garantir ocupação profissional e local de moradia. O processo migratório interno na Região Bragantina, Nordeste do Estado do Pará, não foi diferente da realidade brasileira, verificando-se a migração interna por questões econômicas, e sendo a construção de Estrada de Ferro Belém-Bragança um estímulo para o deslocamento da população negra. A migração da população negra de ex-escravizados para a cidade de Bragança colaborou com a constituição de Quilombos, nomeadamente o Quilombo do América.

\subsection{MIGRAÇÃO INTERNA DO NEGRO NA PROVÍNCIA DE BRAGANÇA, ESTADO DO GRÃO-PARÁ.}

A migração interna no Brasil, na concepção de Tavares (2001, p. 14), pode ser “entendida como um processo natural através do qual o excedente da mão-de-obra utilizado na agricultura era gradualmente redirecionado para a força de trabalho nas cidades”. 
Esse movimento migratório interno no país foi motivado pelo processo de industrialização e urbanização contribuindo para o crescimento de cidades, dando origem as vilas, povoados e comunidades, entre outras formações na Região Amazônica, com destaque à Comunidade do Quilombo do América.

A migração interna do negro de origem africana ganhou destaque na Região Sul, no Baixo Tocantins, Sudeste do Estado do Pará e na Região Bragantina, ponto de encontro e trânsito de migrantes do Estado do Maranhão. Entre esses migrantes que passavam pela região "inclui-se uma parcela significativa de população negra" (SILVA, 2006, p.53). Tal processo migratório interno de deslocamento de pessoas entre Regiões, provocou uma organização no espaço das cidades, favorecendo a população negra na sua fixação na Região Bragantina provocada pela aceleração da "economia extrativista" (CASTRO, 2006, p. 34), entre outros fatores socioeconômicos que contribuíram.

A urbanização da Região Nordeste do Estado do Pará esteve relacionada tanto pela colonização como pela abertura da "Estrada de Ferro Belém-Bragança, recebendo núcleos de colonizadores que foram introduzidos nordestinos, açorianos, espanhóis e franceses para dedicarem-se à agricultura comercial” (CASTRO, 2006, p. 34). Além dos imigrantes de outros países, também existem relatos e indícios da chegada de negros atraídos pelo desenvolvimento local, que foram se somando a população negra já estabelecida na região bragantina.

Assim, consideramos que a construção da Estrada de Ferro pelo processo de urbanização e desenvolvimento das Regiões no Brasil contribuiu para povoar a Região do Nordeste Paraense, especialmente uma faixa de terra, entre a área costeira e o Rio Guamá. Esse movimento sócio econômico pelo viés do trabalho atraiu muitas pessoas em busca de emprego, habitação e condições de vida, que pode ter provocado o povoamento na Região da Amazônia Bragantina pelo negro na formação de comunidades, identidades, culturas, principalmente nas Cidades, nos Mocambos, nas Comunidades Tradicionais e principalmente nos Quilombos.

\section{QUILOMBO DO AMÉRICA ENTRE IDENTIDADE E CULTURAS}

A formação de Quilombos esteve presente na escravidão, pois esses espaços foram constituídos por pessoas escravizadas, os cativos buscavam abrigo como forma de resistência marcada pela violência, repressão, castigo e controle (MOURA, 2014). O Quilombo, como espaço histórico de luta e resistência da população negra, enquadrou política e socialmente na 
formação da identidade negra; neste sentido, a migração negra forçada e migração interna do negro são categorias necessariamente articuladas com a identidade e cultura dessa população. A identidade do negro, na concepção de Moura (2014), não pode ser vista pela forma de submissão, trata-se antes de uma questão de auto identificação, de constituição de comunidades tradicionais influídas pela formação de Quilombos.

A historiografia acerca dos Quilombos se traduz na contemporaneidade por legislações como a Carta Magna de $1988^{8}$ e o Decreto $N^{\circ} 4.887 / 2003^{9}$, que regulamentam o procedimento para identificação, reconhecimento e "titulação das terras ocupadas por remanescentes das comunidades dos quilombos", descrevendo "a caracterização dos remanescentes das comunidades dos quilombos [como sendo] atestada mediante autodefinição da própria comunidade" (BRASIL, 2003).

O Brasil, signatário da Convenção $169^{10}$ da Organização Internacional do Trabalho ${ }^{11}$, estabelece o direito à autodeterminação de Povos e Comunidades Tradicionais, e o Decreto $\mathrm{N}^{\circ}$ 6.040 $2007^{12}$ reconhece que as populações dos Quilombos são Povos Tradicionais, instituindo ainda a política nacional de desenvolvimento sustentável dos povos e comunidades tradicionais. Por isso, os moradores dos Quilombos devem ser considerados "grupos culturalmente diferenciados e que se reconhecem como tais" (BRASIL, 2007). Do mesmo modo, a Lei $\mathrm{N}^{\mathrm{o}} 12.288 / 2010^{13}$ do Estatuto da Igualdade Racial estabelece a garantia para a população negra da "efetivação da igualdade de oportunidades, a defesa dos direitos étnicos individuais, coletivos e difusos e o combate à discriminação e às demais formas de intolerância étnica" (BRASIL, 2010).

O Quilombo do América, no contexto de políticas de ação afirmativas do período de governos progressistas nos inícios do século XXI, estão a desenvolver práticas sociais de valorização da população negra que conduzem à sua autoidentificação como população remanescente de quilombo. Este foi um processo iniciado pela mobilização popular aquando da visita do Representante da Fundação Cultural Palmares (FCP), em 2014 para participar da

\footnotetext{
8 BRASIL. Constituição Federal da República Federativa do Brasil de 1988. Acessado no dia 17/05. https://bit.ly/1dFiRrW.

9 . Decreto $\mathbf{N}^{\mathbf{0}} \mathbf{4 . 8 8 7}$, de 20 de novembro de 2003. Regulamenta o procedimento para identificação, reconhecimento, delimitação, demarcação e titulação das terras ocupadas por remanescentes das comunidades dos quilombos. Acessado no dia 11/05 https://bit.ly/1Gg0jtp

${ }^{10}$ Decreto No $5.051 / 2004$.

11 Convenção $\mathbf{n}^{\circ} \mathbf{1 6 9}$ sobre povos indígenas e tribais e Resolução referente à ação da OIT / Organização Internacional do Trabalho. - Brasília: OIT, 2011. https://goo.gl/eiPyiD

12 . Decreto $\mathbf{N}^{\mathbf{0}} \mathbf{6 . 0 4 0}$, de 7 de fevereiro de 2007.Institui a Política Nacional de Desenvolvimento Sustentável dos Povos e Comunidades Tradicionais. Acessado no dia 10/06/2018. https://bit.ly/160q0Tj

$13 \ldots$ Estatuto da Igualdade Racial - Lei 12288/10 | Lei $\mathrm{n}^{\circ}$ 12.288, de 20 de julho de 2010. https://goo.gl/KCVeoa
} 
assembleia popular de auto reconhecimento, no dia 02 de fevereiro de 2015 , foi publicado no Diário Oficial da União - DOU a certificação onde o Estado Brasileiro reconhece a Comunidade do América enquanto remanescentes quilombolas, dando início a regularização fundiária e a conquista da titulação de sua terra.

Figura 01 - Escola Municipal Américo Pinheiro de Brito na Comunidade Quilombola do América

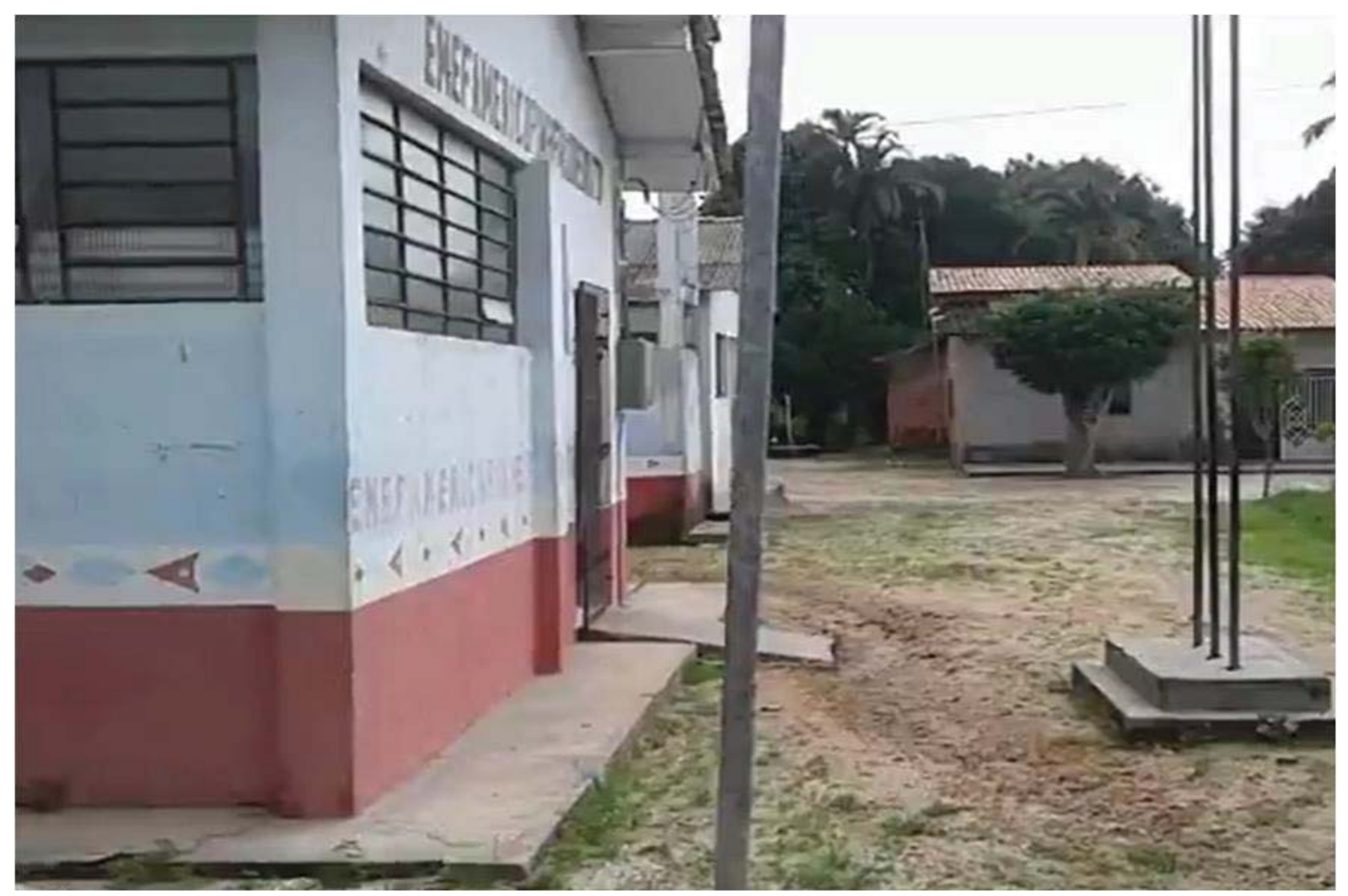

Fonte: Imagens do Vídeo Etnográfico, SANTIAGO K. L. - $2018^{14}$.

A Comunidade do América possui uma escola municipal, EEF, Américo Pinheiro de Brito, que atende as crianças da Educação Infantil e do Ensino Fundamental. O nome da escola e o nome da comunidade são referência a um dos primeiros moradores do quilombo. Este espaço é também utilizado para reuniões da comunidade. Esta passou a ser denominada de Quilombo do América, em 1994, e está situada no Nordeste Paraense, no Município de Bragança/PA, compondo a Unidade de Conservação do Brasil Marinha de Caeté Taperaçu, reserva extrativista vinculada ao Instituto Chico Mendes de Conservação da Biodiversidade.

O ambiente da Comunidade é constituído por um espaço territorial bastante arborizado, onde vivem cerca de 120 famílias, 460 moradores, originalmente de 03 famílias

\footnotetext{
${ }^{14}$ Vídeo Etnográfico "Infância Amazônica no Contexto da Produção de Farinha no Quilombo do América". Publicado na Revista Nova Revista Amazônica - (NRA), em 2018.
} 
de escravos, Brito, Araújo e Fernandes, que "de acordo com as informações de uma das moradoras, os primeiros habitantes da comunidade eram três escravos sobreviventes de um naufrágio, ocorrido na praia de Ajuruteua” (RODRIGUÊS; PEREIRA, 2018, p. 37).

No Quilombo algumas moradias são de alvenaria, casas feitas de lajota e cimento, porém ainda existem algumas casas de taipa, também conhecida como "pau a pique", feitas por meio de uma técnica antiga, que consiste no entrelaçamento de madeiras verticais fixadas no solo e cobertas por barro. Constitui um saber cultural e artesanal desenvolvido ao longo dos anos.

Figura 02 - Casas da Comunidade do Quilombo do América.

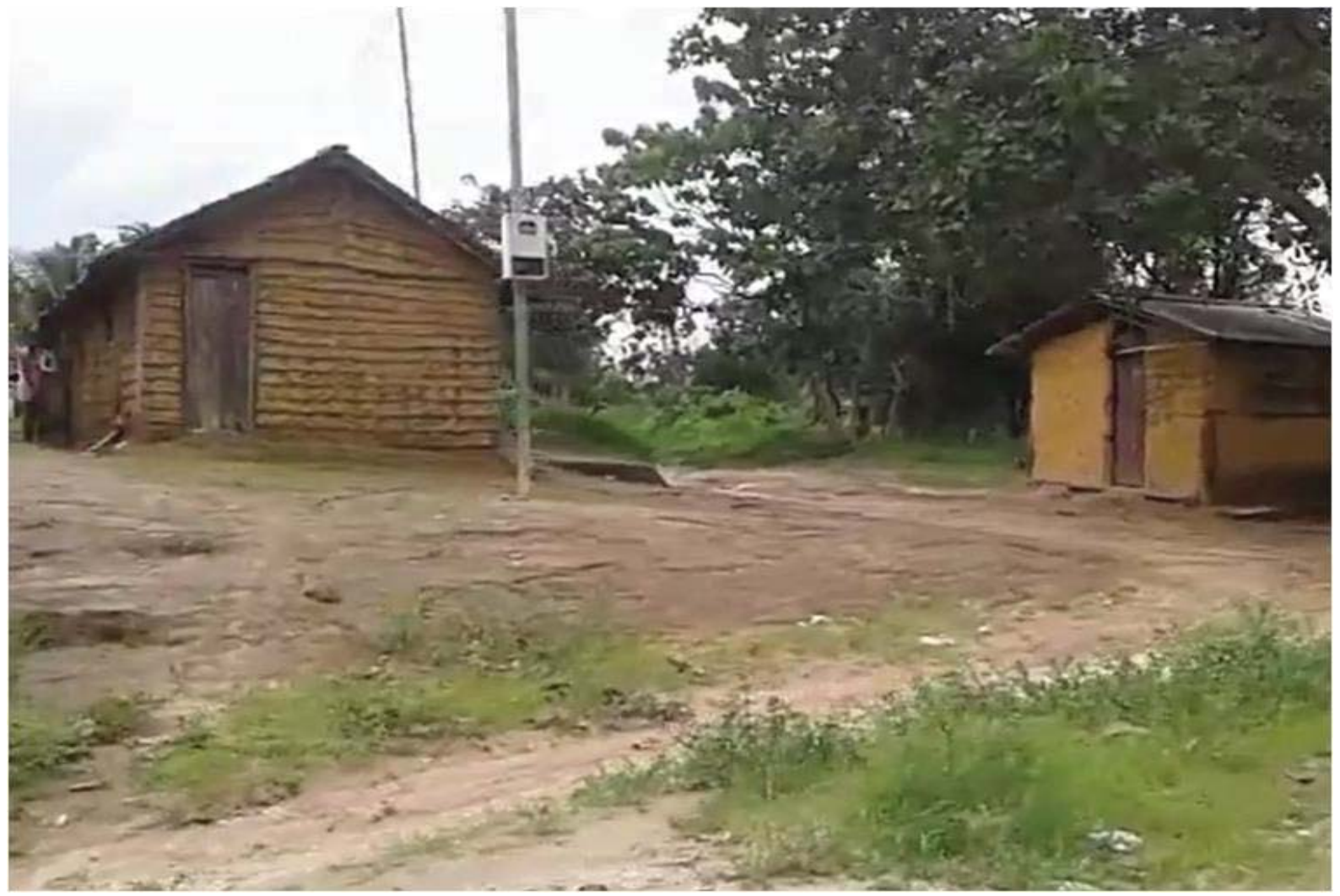

Fonte: Imagens do Ensaio Etnofográfico de SANTIAGO K. L. - $2018^{15}$.

A formação do Quilombo do América na Amazônia bragantina integra um processo de identidade cultural, que se relaciona com os movimentos migratórios e territoriais. Na verdade, as dinâmicas de conformação cultural dizem "aqueles aspectos de nossas identidades que surgem de nosso "pertencimento" a culturas étnicas, raciais, linguísticas, religiosas e,

15 Ensaio etnofotográfico produzido como parte da avaliação na disciplina Linguagem através da imagem, ministrada pelo Prof. Dr. Daniel dos Santos Fernandes, do Programa de Mestrado em Linguagem e Saberes da Amazônia - (PPLSA-UFPA). 
acima de tudo, nacionais" (HALL, 2006, p. 08) e estão relacionadas com a uma concepção de “culturas étnico-raciais" (COELHO, 2014). Por sua vez, a cultura popular se constitui pelos ritmos musicais, culinária, o uso de vestimentas, a forma de manuseio da agricultura em constantes modificações, carregando "elementos do novo e do velho" (HALL, 2003, p. 254).

Figura 03 - Produção de Farinha no Quilombo do América.

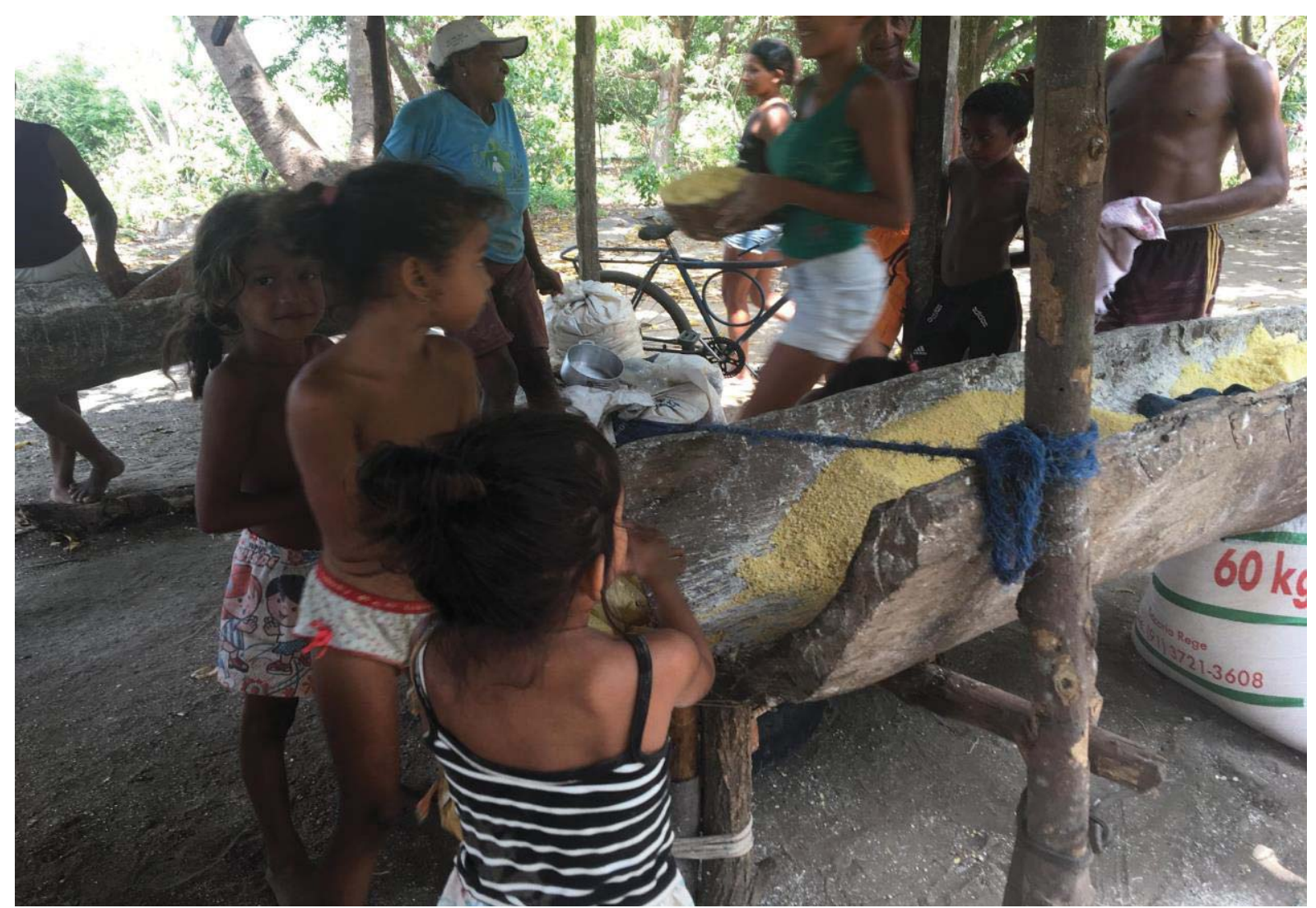

Fonte: Imagens do Ensaio Etnofográfico de SANTIAGO K. L.- 2018.

A produção de farinha envolve toda a família, incluindo os mais jovens, que não trabalham na sua produção, mas que estão em redor da família aprendendo a prática do cultivo, manejo e beneficiamento da mandioca.

As práticas culturais e tradicionais desenvolvidas pelo quilombo funcionam tendo como base econômica as pessoas da comunidade e desenvolvem-se por meio do trabalho em olarias da região, da agricultura familiar, da pesca e do extrativismo do caranguejo. Outras práticas desenvolvidas são o cultivo da macaxeira, da mandioca e da produção de farinha, dentro de um contexto social produzido pelos moradores do quilombo, ainda que de forma rústica inseridas num território (SANTIAGO; SMITH JÚNIOR; SOUZA, 2018). Um trabalho desenvolvido de forma artesanal, com elementos tradicionais, passados de pais para filhos. 
Assim, a cultura da população do Quilombo do América atravessa o manuseio da terra e da agricultura como trabalho para garantir a subsistência, um trabalho coletivo essencial na produção de farinha. Esses povos são produtores tradicionais, cujas características de "formação histórica pela condição que ocupam na estrutura social e os trezentos anos de existência, permitem caracterizá-los como o "campesinato histórico" da Amazônia" (LIMA; POZZOBON, 2005, p. 60).

As práticas culturais que definem a identidade cultural dos moradores do América na concepção de Morais (2015) refletem-se nas narrativas dos moradores na sua qualidade de sujeitos da Comunidade Remanescente Quilombola do América. Veremos a seguinte narrativa de uma moradora sobre os motivos da sua autodefinição enquanto Quilombola:

\footnotetext{
há muito tempo... desde quando eu tinha uns vinte anos....porque a gente quer ser quilombo... porque o terreno é grande... e a gente acha melhor se denominar de quilombo... o terreno era grande... hoje a gente já não pode mais planta... aquele gordo invadiu... nosso terreno era até na beira da pista... tudo aqui é da minha família... desde do meu avôs... dos meus pais ( MORAIS, 2015, p.08). ${ }^{16}$
}

As narrativas dos moradores do Quilombo do América são um importante elemento definidor de sua identidade, resumindo perfeitamente a dialética da memória e da identidade que se conjuga, se nutrem mutuamente, se apoiam uma na outra para produzir uma trajetória de vida, uma história, um mito, uma narrativa" (CANDAU, 2012, p. 16)

A pesquisa aponta que a sua constituição enquanto quilombo, contribui como espaço de luta e resistência ideológica, identitária e cultural do povo negro, indica uma concepção de identidade relacionada às narrativas dos moradores pela ideia de pertencimento ao local estabelecido, na relação com a natureza e na utilização dos recursos naturais como forma de subsistência, na utilização dos espaços físicos e sociais da comunidade.

Os estudos também revelam, para a formação de uma identidade cultural presente em suas manifestações religiosas, em suas vestimentas, na sua alimentação e educação, desenvolvidas no espaço do Quilombo. A identidade de matriz africana na constituição e formação da identidade afro-brasileira está presente nos Quilombos, identificadas nas publicações e bibliografias consultadas. Essa experiência e vivência na comunidade, na utilização dos recursos presentes na natureza, garantem a sobrevivência de muitas famílias, em destaque (Figura 04) para a família de Dona Ana Maria que narrou a forma como trabalham o cultivo da mandioca e fabricação da farinha.

16 Pesquisa realizada em 2014 por Morais (2015), durante a realização da Assembleia da Comunidade do América para definição de seu autoreconhecimento. 
Figura 04 - Entrevista com a Moradora do Quilombo do América.

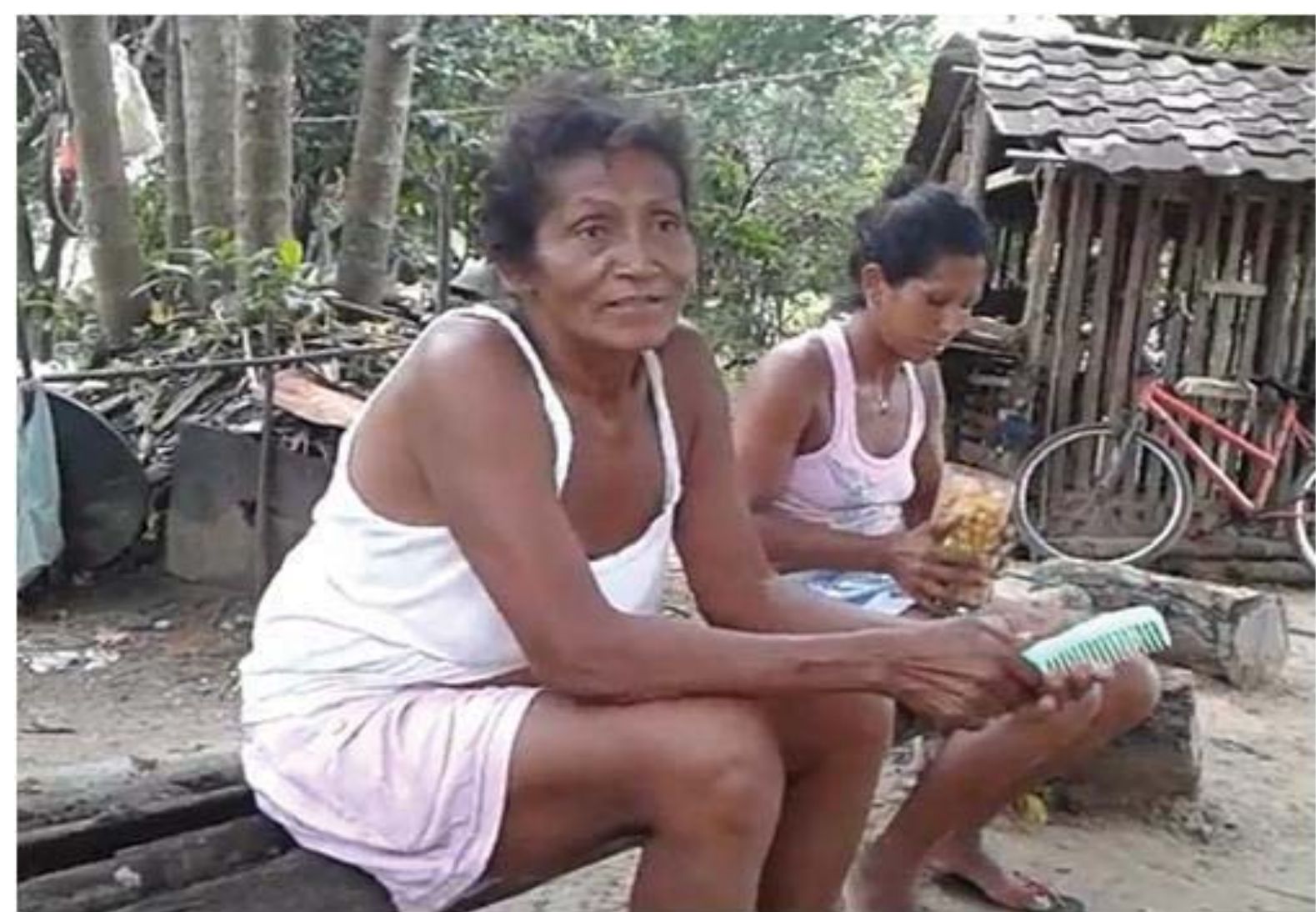

Fonte: Imagens da Dona Ana Maria do Vídeo Etnográfico, SANTIAGO; SMITH JUNIOR; SOUZA (2018). ${ }^{17}$

Os moradores da Comunidade do América vivenciam experiências culturais, trabalho educativo na utilização de recursos da natureza, que garantem a eles o modo de subsistência para muitas famílias, uma vez que a forma de trabalho é útil no cultivo da mandioca e fabricação da farinha. Portanto, diante dos dados apresentados é possível identificar os elementos propostos inicialmente na pesquisa, considerando que são dados inicias de uma pesquisa em fase de construção, que apresentam alguns indicativos, que contribuem para a construção de uma pesquisa mais ampla sobre a temática proposta, neste sentido, partimos para as considerações finais.

\section{CONSIDERAÇÕES FINAIS}

No decorrer desta pesquisa percebemos os conceitos de migração como um deslocamento no espaço territorial causado por várias motivações, que difere da população negra africana, por se tratar de um processo obrigatório e violento, a migração forçada.

\footnotetext{
${ }^{17}$ Dona Ana Maria no Vídeo Etnográfico, falando sobre a produção de farinha no Quilombo.
} 
Nesse sentido, a migração negra obrigatória foi marcada historicamente, por mais de três séculos, por conflitos e luta dos negros pela liberdade e contra o perverso sistema escravagista brasileiro. Assim, a população negra nesse contexto de negação viu a necessidade de migrar internamente, por fatores de exclusão social, em que o Estado não a incorporou no mundo do trabalho, ficando à margem da sociedade, sem moradia e condições de sobrevivência.

A população negra deu início a uma dinâmica de migração interna que consistiu em deslocações da cidade para o campo e do campo para a cidade, de região para região, de Estado para Estado, contribuindo de forma preponderante para o processo de urbanização das cidades brasileiras e das cidades Amazônicas, bem como, migraram para a Região Bragantina, como a Cidade de Bragança, no Estado do Pará.

Em Bragança, Pará constituíram à Comunidade do América, que passou a ser reconhecida como Quilombo do América. A formação desse Quilombo representa para os negros moradores da região uma questão de identidade e cultura produzidas pela população negra. Assim, consideramos que estudar a Comunidade Quilombola do América tem grande valor acadêmico, o sentido de se produzir outro conhecimento epistemológico, um rico valor social ao identificar as origens e a constituição dos povos remanescentes deste Quilombo.

Por isso, reiteramos que o processo de fixação da população negra integrou, também, um processo identitário por meio de autodefinição enquanto descendentes quilombolas, reafirmando a sua ancestralidade e afirmando a sua pertença. Isso significa dizer que a hipótese de a constituição do Quilombo do América na Região Bragantina se deve a fatores econômicos relacionados a migração do negro.

\section{REFERÊNCIAS}

BEZERRA NETO, José Maia. Escravidão Negra no Pará: (Séculos XVII - XIX) /José Maia Bezerra Neto. _ 2a ed. _ Belém: Paka-Tatu, 2012.

CASTRO, Edna. Escravos e senhores de Bragança (Documentos históricos do século XIX, Região Bragantina, Pará) / Edna Maria Ramos de Castro (Organização). _ Belém: NAEA, 2006.

COELHO, Wilma de Nazaré Baía. A Lei no 10.639/2003: Pesquisas e Debates / Wilma de Nazaré Baía Coelho...[et al.] (Organizadores). - São Paulo: Editora Livraria da Física, 2014. (Coleção Formação de Professores \& relações étnico-raciais).

COSTA, Emília Viotti da. Da Monarquia à República - momentos decisivos”, Emília Viotti da Costa. -8 ed. ver. E ampliada. São Paulo: Fundação Editora UNESP, 2007. 
CANDAU, Joel. Memória e Identidade. São Paulo: Editora. Contexto. 2012.

GLEDHILL, Helen Sabrina. Travessias racialistas no Atlântico Negro: reflexões sobre Booker T. Washington e Manuel R. Querino/ Helen Sabrina Gledhill. - 2014. 302 f. : il.

HALL, Stuart. Da diáspora: Identidades e mediações culturais / Stuart Hall; Organização Liv Sovik; Tradução Adelaine La Guardia Resende ... letall.- Belo Horizonte: Editora UFMG; Brasília: Representação da UNESCO noBrasil, 2003. 4M p. (Humanitas).

HALL, Stuart. A identidade cultural na pós-modernidade / Stuart Hall; tradução Tomaz Tadeu da Silva, Guaracira Lopes Louro-11. ed. -Rio de Janeiro: DP\&A, 2006.

KLEIN, H. S. Migração Internacional na História da América. In: FAUSTO, Boris (org), Fazer a América. São Paulo: EDUSP, 2000. p. 13-31.

LIMA, Deborah. POZZOBON, Jorge. "Amazônia socioambiental. Sustentabilidade ecológica e diversidade social". Estudos avançados 53 - DossiêAmazônia brasileira I. São Paulo: Instituto de Estudos Avançados/ USP, jan-abril. 2005, p. 45-76.

MOURA, Clovis. Rebeliões da Senzala. 5a Edição. Editora Anita Garibaldi. Fundação Maurício Grabois. São Paulo-SP, 2014.

MORAIS, Elizabeth Conde de. A Identidade Africana presente na Comunidade Quilombola do América. 2015. 12 f. Monografia Especialista em Políticas de Promoção da Igualdade Racial na Escola. Universidade Federal do Pará - Belém/PA.

RODRIGUÊS. Márcia Taynãn do Rosário; PEREIRA. Silvana Ribeiro. Ser ou não ser Quilombola, Eis a Questão: Um Estudo sobre ideologia na comunidade Quilombola América - Bragança - Pará - Com base na análise do discurso. 2018. 87 f. Trabalho de Conclusão de Curso. Faculdade de Letras - Universidade Federal do Pará - Campus de Bragança.

SANTIAGO. K. L.; SMITH JUNIOR. F. P.; SOUZA. A. P. V. e. Infância Amazônica no Contexto da Produção de Farinha no Quilombo do América. Nova Revista Amazônica Ano VI - Volume 1 - abril. 2018- ISSN: 2318-1346.

SAYAD. A. A imigração ou os paradoxos da alteridade. / Prefácio Pierre Bourdieu; Tradução Cristina Muracho. - São Paulo: Editora da Universidade de São Paulo, 1998.

SILVA. Idelma Santiago da. MIGRAÇÃO E CULTURA NO SUDESTE DO PARÁ: Marabá (1968-1988). 2006. 181f. (Dissertação de Mestrado) Curso de Mestrado em História da Faculdade de Ciências Humanas e Filosofia da Universidade Federal de Goiás.

SMITH JÚNIOR, Francisco Pereira. Imigração espanhola na Amazônia: as colônias agrícolas e o desenvolvimento socioeconômico do Nordeste paraense (1890-1920). 2012. 212 f. Tese (Doutorado) - Universidade Federal do Pará, Núcleo de Altos Estudos Amazônicos, Belém, 2012. Programa de Pós-Graduação em Desenvolvimento Sustentável do Tropico Úmido. 
TAVARES, Gilson Q. Migração Interna Populacional e sua Participação no Desenvolvimento Regional No Final do Século XX. 2001. 107 f. (Dissertação de Mestrado, apresentada à Escola de Administração Pública), Fundação Getúlio Vargas - Rio de Janeiro 2001. 